\title{
PV Output Power Fluctuations Smoothing and Optimum Capacity of Energy Storage System for PV Power Generator
}

\author{
Tomonobu Senjyu ${ }^{1}$, Manoj Datta ${ }^{1}$, Atsushi Yona ${ }^{1}$, Toshihisa Funabashi ${ }^{2}$, and Chul-Hwan Kim $^{3}$ \\ ${ }^{1}$ Department of Electrical and Electronics Engineering \\ University of the Ryukyus, 1 senbaru Nishihara-cho Nakagami, Okinawa 903-0213, Japan \\ Phone: +81988958686, E-mail: b985542@tec.u-ryukyu.ac.jp, k068472@eve.u-ryukyu.ac.jp \\ ${ }^{2}$ Meidensha Corporation, ThinkPark Tower, 2-1-1 Osaki, \\ Shinagawa-ku, Tokyo 141-6029, Japan \\ Phone: +810364207208, E-mail: funabashi-t@mb.meidensha.co.jp \\ ${ }^{3}$ School of Electrical and Computer Engineering, \\ Sungkyunkwan University, Suwon City 440-746, Korea \\ E-mail: chkimskku@yahoo.com
}

\begin{abstract}
In this paper, an Energy Storage System (ESS) based control method is proposed to reduce the PV output power fluctuations, which in turn will reduce the frequency deviations of the power system introduced by large penetration of PV power. The ESS control model introduced here will maintain the energy storage ratio of the ESS near $50 \%$. This will increase the life time of the ESS as well as will decrease the maintenance cost of the ESS. A local search algorithm is also provided with this ESS control model to search the optimal capacity of the ESS required for smoothing the PV output power fluctuations and to find the minimum capital cost. A cost comparison is shown to realize the performance of the search algorithm.
\end{abstract}

\section{Key words}

Capital cost, Energy Storage System, Optimal capacity, PV output power smoothing.

\section{Introduction}

In recent times, Global warming is a burning issue as the $\mathrm{CO}_{2}$ density increased highly in the atmosphere. Therefore, clean and renewable energy sources must be introduced to reduce the $\mathrm{CO}_{2}$ density. Among various renewable energy systems, PV systems are expected to play a promising role as a clean power electricity source in meeting future electricity demands. However, the power output of PV systems fluctuates depending on weather conditions, season, and geographic location. In the future, when a significant number of PV systems will be connected to the grids of power utilities, power output fluctuation may cause problems like voltage fluctuation and large frequency deviation in electric power system operation [1]-[3]. Therefore, for the penetration of large PV system's output power in the utility without reduction of the reliability of utility power systems, suitable measures must be applied to the PV systems side.

On the PV system side, energy storage devices like batteries can be used as smoothing devices for a PV system's output. There have been investigations aimed at improving the performance of PV systems equipped with batteries [4]-[9]. However, energy storage device increases capital cost, as it needs maintenance. The maintenance cost mainly depends on charge/discharge action of battery. Therefore, controlling the charge/discharge action along with maintaining the energy storage ratio near $50 \%$ is a issue need to be addressed. Besides, optimal capacity and minimum capital cost of the ESS needed to reduce the PV out put power fluctuations should also be investigated. However, in previous investigations, the optimal size of battery and battery parameters for charge/discharge action are not considered.

In this paper, to address the above given issue, a control methodology for ESS along with PV generator is presented, which will maintain storage energy ratio of the battery up to $50 \%$ and will select optimal size of the battery needed for smoothing PV output power fluctuations. From the simulation results, it has been found that the proposed method works well to reduce the PV output power fluctuations and also selects the optimal ESS capacity needed for it maintaining the energy storage ratio near $50 \%$.

\section{Small Power System}

The concept of small power utility in this paper is shown in Fig. 1. The small power utility consists of the diesel generators and PV systems equipped with ESS that generate power to supply the demand. In addition, it is assumed that the small power utility is not connected to large power utility and it is always operated independently like the power system in an isolated island. The small power system model which consists of diesel generator in detail, PV power generation system, load and Energy Storage system, and load is shown in Fig. 2 where $S_{i}$ is the insolation, $P_{\max }^{*}$ is the maximum power

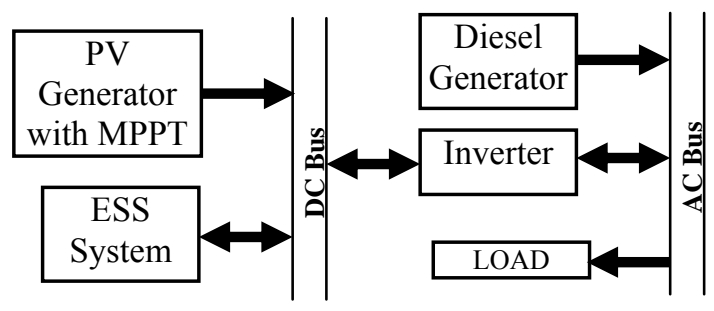

Fig. 1. Small power utility. 


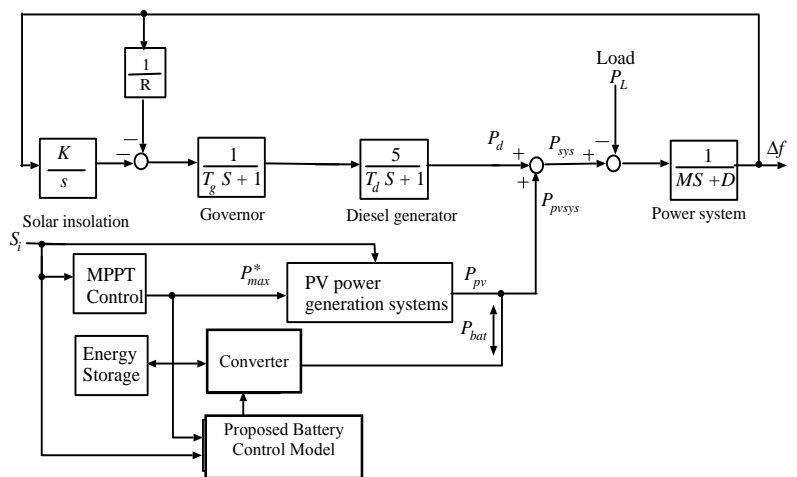

Fig. 2. Small power system model.

point tracking (MPPT) command power, $P_{b a t}$ is the battery power, $P_{p v s y s}$ is the PV power by PV supplied to the power system, $P_{d}$ is generated power by diesel generators, $R$ is the speed regulation, $T_{g}$ is the governor time constant, $T_{d}$ is the diesel generator time constant, $P_{L}$ is the load, $M$ is the inertia constant, $D$ is the damping constant, $u$ is the input to the governor, $\Delta f$ is the frequency deviation of small power utility.

The control algorithm [10] for the inverter shown in Fig. 1 adopted here is very simple. The inverter output voltages and currents are sensed and transformed from 3phase to synchronously rotating 2-phase. The command currents are generated dividing the output power command by sensed inverter voltage. Then the error between command inverter current and actual inverter current is processed through a PI controller to generate the PWM pulses. For maximum power extraction, the output power command is generated by maximum power point tracking algorithm. For simple structure and less costly implementation, a Perturbed and Observed (P\&O) [11] algorithm was chosen in the present structure.

As the design of power converter and the control system is significantly influenced by the solar module characteristics, these will briefly reviewed here. The solar module is a nonlinear device and can be represented as a current source model, as shown in Fig. 3. The traditional $I-V$ characteristics of a solar module are given by the following equation [12]:

$$
I_{0}=N_{p} N_{s} I_{g} I_{\text {sat }}\left\{\exp \frac{q V_{0}}{A K T_{a}}\left(V_{0}+\frac{N_{s} R_{s} I_{0}}{N_{p}}\right)-1\right\}
$$

where $I_{0}$ and $V_{0}$ are the output current and output voltage of the solar module, respectively, $I_{g}$ is the generated current under a given insolation, $I_{\text {sat }}$ is the reverse saturation current, $q$ is the charge of an electron, $K$ is the Boltzmann's constant, $A$ is the ideality factor, $T_{a}$ is the temperature $(\mathrm{K}), N_{p}$ is the number of cells in parallel, $N_{S}$ is the number of cells in series, $R_{S}$ is the internal series resistance, and $I_{r s h}$ is the current due to intrinsic shunt resistance of the solar module.

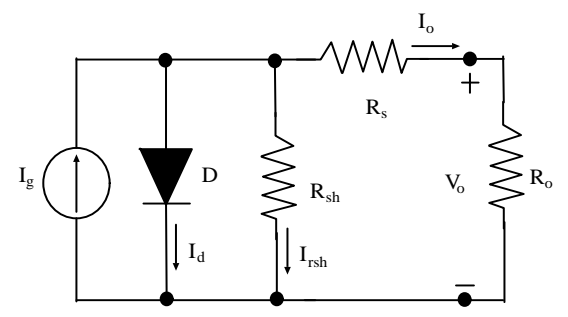

Fig. 3. Equivalent circuit of a solar module.

The solar module output power is given by the following equation:

$$
P_{0}=V_{0} I_{0}
$$

Equations given in (1) and (2) are used in the development of computer simulations for the solar module. The MATLAB/SIMULINK is used. Fig. 4(a) and (b) shows the simulated ampere-volt and power-volt curves of the solar module for different insolation at constant temperature. Figs. 4(c) and (d) show the simulated ampere-volt and power-volt curves of the solar module for different temperature at constant insolation. From these curves, it is observed that the output characteristics of the solar module are nonlinear and vitally affected by the variation of insolation. However, variation of temperature slightly affects the output characteristics of solar module. Therefore, for the present case study, insolation and temperature variation effects both are taken in to account to model the solar array.

\section{Battery Control Method}

In order to smooth PV output power fluctuations, average PV power is generated from MPPT generated PV power through a low pass filter. The average PV power lis given by the following equation

$$
P_{\text {avg }}=P_{\max } f(s)
$$

where $f(s)=\frac{0.9}{20 s+1}$

This average power is used as command power for the battery control system. Therefore, this command power
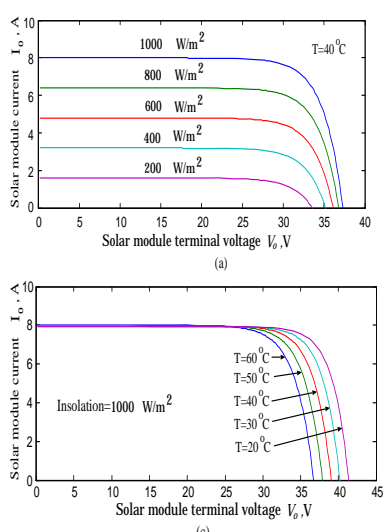
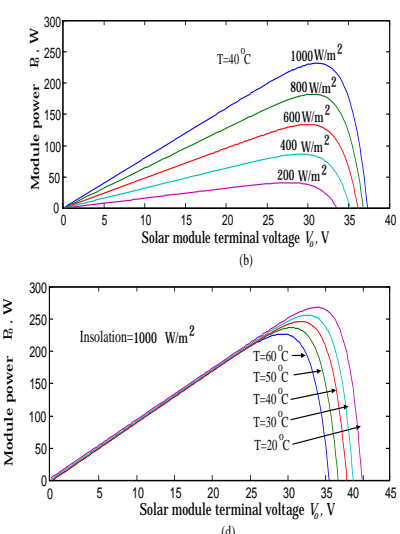

Fig. 4. Solar module characteristic curves. (a) and (c) Current-voltage curves. (b) and (d) Power-voltage curves. (For (a) and (b) temperature is constant; for (c) and (d) insolation is constant). 
will be achieved from the PV system by charging/discharging action of the Battery. The proposed battery control model is shown in Fig. 5.

At first the proposed model calculates PV output power fluctuations by the given below equation.

$$
\Delta P_{\text {pvsys }}=P_{\text {avg }}-P_{\max }
$$

where $\Delta P_{\text {pvsys }}$ is $\mathrm{PV}$ output power fluctuations. To reduce the charge/discharge action of the battery, a definite value for the dead zone $D_{\text {zone }}$ is set. Dead zone will activate when $\Delta P_{p v s y s}$ is greater than the dead zone value. Therefore, if the dead value is set big, small PV power fluctuations will remain in the system. On the other hand, if the dead zone value is set small, PV output power fluctuations will be smoothed well, however, battery will experience rapid charge/discharge action. So, choosing the optimal parameter for battery control system is a vital issue. From Fig. 5, it can be seen that correction power $P_{C}$ is added with dead zone. Then, battery output $P_{b a t}$ is computed through the limiter whose maximum range is the converter capacity $C_{I}$. Battery experiences charge/discharge action when $P_{b a t}$ becomes positive/negative. The battery's remaining capacity $W_{b a t}$ is calculated through integration. This integrator is also considered as a limiter whose maximum range is the battery capacity $C_{b a t}$. The remaining battery capacity $W_{b a t}$ is passed through a 2-D lookup table to maintain the storage ratio $\xi\left(=\frac{W_{b a t}}{C_{b a t}} 100 \%\right)$ to near $50 \%$. The lookup table is shown in Fig. 6. The lookup table produces a correction value $M$. The product of correct value $\mathrm{M}$ and converter capacity $C_{I}$ becomes the correct power $P_{C}$.

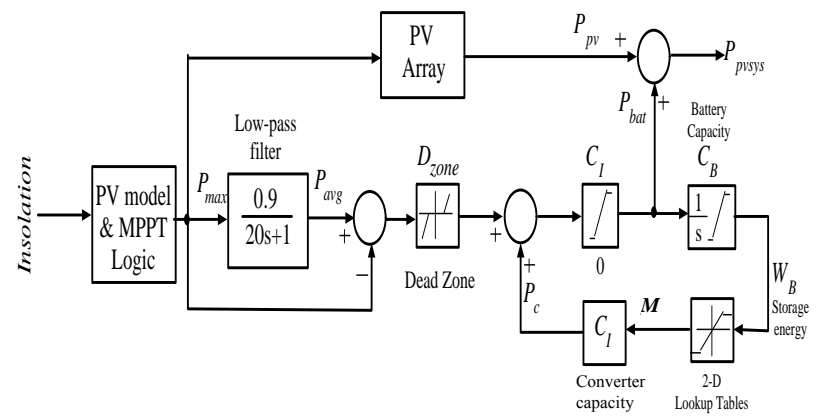

Fig. 5. Proposed battery control model.

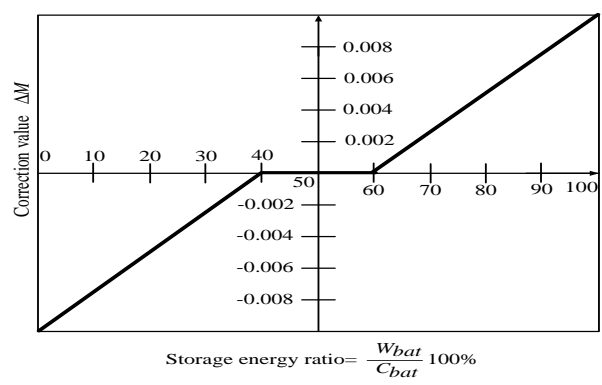

Fig. 6. Lookup table for correction value $M$.

\section{Optimization of Battery Size and Cost}

When searching the optimal size of the battery capacity and converter capacity, which will maintain minimum capital cost, optimal control parameters for battery control model should be searched. The searching algorithm is shown in Fig. 7.

Objective function and constraint condition are given in (5) and (6). Capital cost $C_{\text {cap }}$ is calculated from (5). Here $C_{p}$ is the per kWh capacity price of the battery and $C_{w}$ is the per kW capacity of the converter [13].

$$
\begin{array}{r}
\min C_{\text {cap }}=C_{B} C_{p}+C_{I} C_{w} \\
\Delta P_{p v s y s \text { max }} \geq \Delta P_{p v s y s}
\end{array}
$$

The searching process for optimization is described as follows.

Step 1: Maximum output power fluctuation tolerance limit $\Delta P_{\text {pvsysmax }}$ is set.

Step 2: In this steps control parameters of ESS ( $M$, $D_{\text {zone }}$ ) are set.

Step 3: The charge/discharge action of battery is performed. $\Delta P_{p v s y s}$ is calculated. It searches $C_{B}$ and $C_{I}$ to minimize the capital cost using the local search which is shown in Fig. 8.

This step increases by a large width when it searches for optimal battery and converter capacities. Secondly, it searches by small width of increase. As shown in Fig. 8, this process iterated twice according to objective function. In order to prevent the convergence in local solution, it searches solution of three higher ranks to minimize the capital cost.

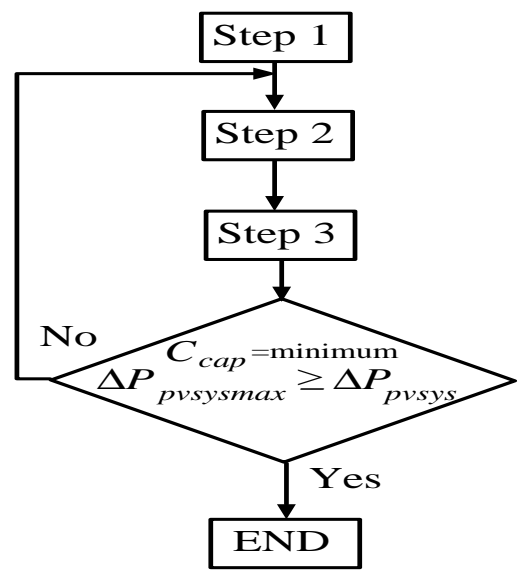

Fig. 7. Algorithm used for optimization .

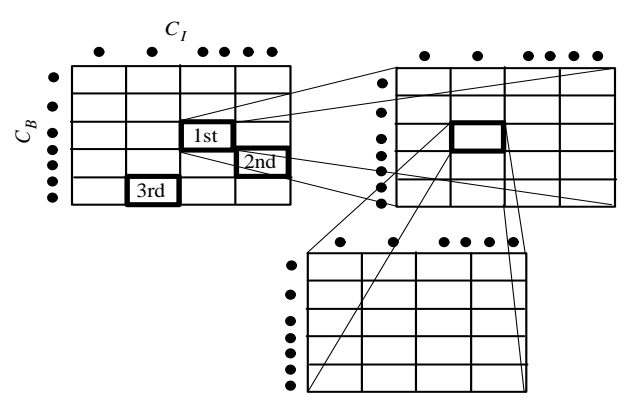

Fig. 8. Local search on step 3 . 
Step 4: The result of step 3 is evaluated. If it satisfies at end conditions, process terminated else it goes to step 2 .

\section{Simulation Results}

In this paper, the effectiveness of output power leveling of PV array and frequency deviation reduction of power system using the proposed method is examined by simulation with system model and parameters as mentioned in [12]-[16]. In order to use parameters of real PV system given in [15], [16], the rated output power of the PV array is $241 \mathrm{~kW}$. Simulation parameters of power system, PV array, power converter and PI controller are shown in TABLE III. Here, integral time $T$ is $100 \mathrm{~s}$, sampling time $T_{S}$ to obtain discrete value of output power command is $10 \mathrm{~s}$, and sampling time of PI controller is 1 ms. Simulation time is 30 minutes and the averaging sample time of insolation is $20 \mathrm{~s}$.

TABLE II shows the simulation results for the optimization algorithm.

TABLE I. Simulation Parameters

\begin{tabular}{|c|c|c|}
\hline \multicolumn{3}{|c|}{ Parameters of small power system } \\
\hline Inertia constant, $M$ & \multicolumn{2}{|c|}{$0.150 \mathrm{puMW} \cdot \mathrm{s} / \mathrm{Hz}$} \\
\hline Damping constant, $D$ & \multicolumn{2}{|c|}{$0.008 \mathrm{puMW} / \mathrm{Hz}$} \\
\hline Governor time constant, $T_{q}$ & \multicolumn{2}{|c|}{$0.10 \mathrm{~s}$} \\
\hline Time constant, $T_{t}$ & \multicolumn{2}{|c|}{$0.25 \mathrm{~s}$} \\
\hline Time constant, $T_{r}$ & \multicolumn{2}{|l|}{$8.0 \mathrm{~s}$} \\
\hline Speed regulation, $R$ & \multicolumn{2}{|c|}{$2.5 \mathrm{~Hz} / \mathrm{puMW}$} \\
\hline \multicolumn{3}{|c|}{ Parameters of PV array } \\
\hline Rated output power & \multicolumn{2}{|c|}{$241 \mathrm{~kW}$} \\
\hline Open circuit voltage & \multicolumn{2}{|c|}{$588.80 \mathrm{~V}$} \\
\hline Short circuit current & \multicolumn{2}{|c|}{$520.37 \mathrm{~A}$} \\
\hline Number of modules in series & \multicolumn{2}{|c|}{16} \\
\hline Number of modules in parallel & \multicolumn{2}{|c|}{65} \\
\hline Total number of cells & \multicolumn{2}{|c|}{62,400} \\
\hline \multicolumn{3}{|c|}{ Parameters of PV module } \\
\hline \multicolumn{2}{|l|}{ Rated output power } & $231.58 \mathrm{~W}$ \\
\hline \multicolumn{2}{|l|}{ Open circuit voltage, $V_{o C}$} & $36.30 \mathrm{~V}$ \\
\hline \multicolumn{2}{|l|}{ Short circuit current, $I_{S C}$} & $7.99 \mathrm{~A}$ \\
\hline \multicolumn{2}{|l|}{ Shunt resistance, $R_{S h}$} & $50 \Omega$ \\
\hline \multicolumn{2}{|l|}{ Series resistance, $R_{S}$} & $5 \Omega$ \\
\hline \multicolumn{2}{|l|}{ Ideality factor, $A$} & 1.450 \\
\hline \multicolumn{2}{|l|}{ Inverse Saturation Current, $I_{o r}$} & $3.047 \mathrm{e}-07 \mathrm{~A}$ \\
\hline \multicolumn{2}{|c|}{ S.C. current temperature constant, $I_{t}$} & $1.73 \mathrm{e}-03 \mathrm{~A} /{ }^{0} \mathrm{~K}$ \\
\hline \multicolumn{2}{|l|}{ Reference temperature, $T_{r e f}$} & $25^{\circ} \mathrm{C}$ \\
\hline \multicolumn{2}{|l|}{ Boltzman's constant, $K$} & $1.38 \mathrm{e}-23$ \\
\hline \multicolumn{2}{|l|}{ Charge of an electron, $q$} & $1.602 \mathrm{e}-19 \mathrm{C}$ \\
\hline \multicolumn{2}{|l|}{ Bandgap voltage, $E_{q}$} & $1.11 \mathrm{eV}$ \\
\hline \multicolumn{2}{|l|}{ Number of cells in series, $N_{S}$} & 60 \\
\hline \multicolumn{2}{|l|}{ Standard insolation, $S_{i}$} & $1,000 \mathrm{~W} / \mathrm{m}^{2}$ \\
\hline \multicolumn{2}{|l|}{ Dimension } & $0.75 \mathrm{~m}^{3}$ \\
\hline
\end{tabular}

TABLE II. Optimization results

\begin{tabular}{|c|c|c|c|c|}
\hline Sl. & Case 1 & Case 2 & Case 3 & Case 4 \\
\hline$\Delta M$ & 0.002 & 0.001 & 0.002 & 0.007 \\
\hline $\boldsymbol{D}_{\text {zone }}$ & 0 & 0 & 0 & 0 \\
\hline$\Delta P_{\text {pvsys }}$ & $\pm 34 \mathrm{~kW}$ & $\pm 12 \mathrm{~kW}$ & $\pm 11 \mathrm{~kW}$ & $\pm 15 \mathrm{~kW}$ \\
\hline$C_{B}$ & $60 \mathrm{kWh}$ & $160 \mathrm{kWh}$ & $180 \mathrm{kWh}$ & $200 \mathrm{kWh}$ \\
\hline$C_{I}$ & $130 \mathrm{~kW}$ & $200 \mathrm{~kW}$ & $170 \mathrm{~kW}$ & $230 \mathrm{~kW}$ \\
\hline Cost & $237 \mathrm{k} \$$ & $249 \mathrm{k} \$$ & $381 \mathrm{k} \$$ & $485 \mathrm{k} \$$ \\
\hline
\end{tabular}

The comparative simulation results of the proposed control and MPPT control [4] are shown in Fig. 9 by solid line and dotted line respectively. Insolation and load are shown in Figs. 9 (a) and (b) respectively. Fig 9 (c) shows the PV power produced by MPPT control and proposed control. From, Fig. 9 (c), it can be said that PV power produced by proposed method is levelled by battery charging/discharging action.

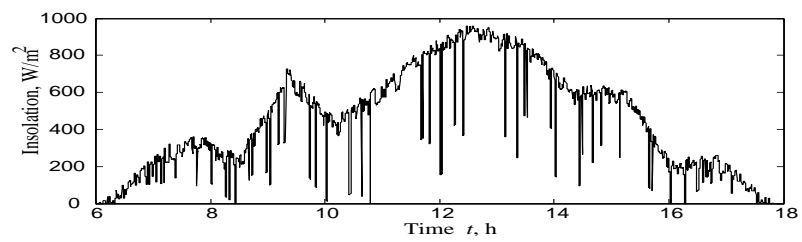

(a) Typical daily insolation

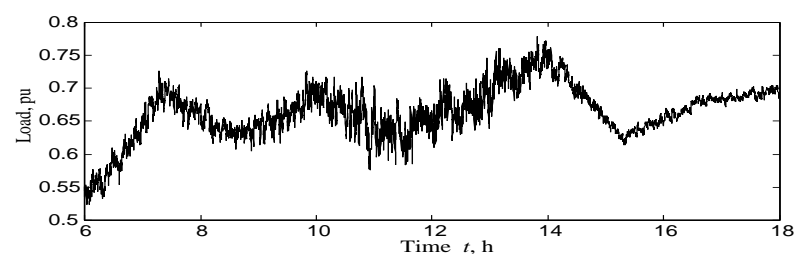

(b) Typical daily load

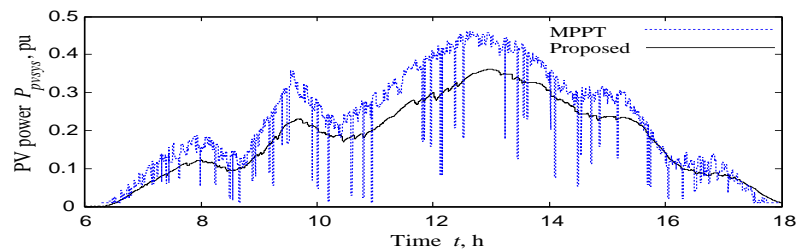

(c) PV power

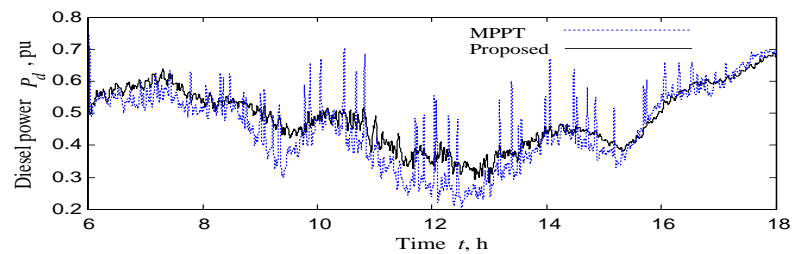

(d) Diesel power

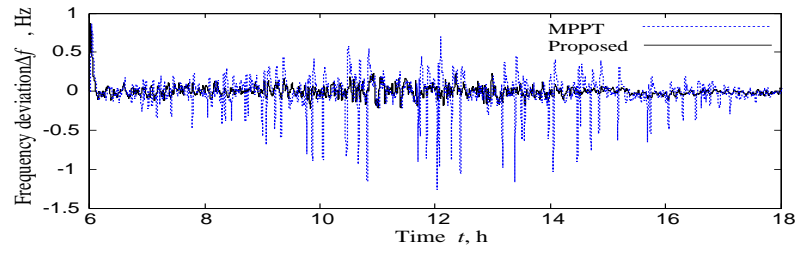

(e) Frequency deviations

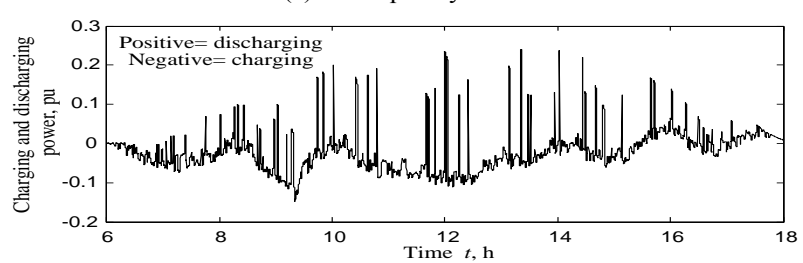

(f) Battery charging/discharging

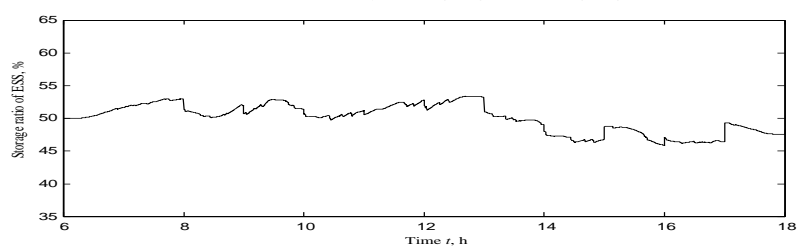

(g) Energy storage ratio

Fig. 9. Comparative simulation results of the proposed control and MPPT control 
Fig. 9 (d) shows diesel power where diesel power produced by proposed method fluctuates less than the diesel power produced by MPPT control. Fig. 9 (e) shows the frequency deviations where frequency deviations produced by MPPT control are $\pm 1 \mathrm{~Hz}$. On the other hand, frequency deviations produced by proposed method is almost near to zero. Therefore, it can be said that the proposed method is effective to reduce the frequency deviation of the utility. Fig. 9 (f) shows battery charging/discharging action. Fig. 9 (g) shows the storage energy ratio which is maintained below $50 \%$, thus, it will reduce maintenance cost for the battery. So overall capital cost will be reduced as the optimum battery and converter capacity is used by the proposed method.

\section{Conclusion}

In this paper, PV output power fluctuations are levelled using the proposed methodology through battery charge/discharge action and the optimal size of the battery is calculated to minimize the capital cost. In the optimization problem of Energy Storage System (ESS), the control parameter for ESS is selected in all combinations and local search is performed to find the optimal size of the battery. The proposed method is compared with conventional MPPT. From the simulation results, it has been found that the proposed method is able to achieve the required control parameters for ESS and the optimal battery and converter capacities to minimize the total cost and to minimize the frequency deviations.

\section{References}

[1] S. Yanagawa, T. Kato, K. Wu, A. Tabata, and Y. Suzuoki, "Evaluation of LFC capacity for output fluctuation of photovoltaic generation systems based on multi-point observation of insolation," in Proc. IEEE Power Engineering Society Summer Meeting, 2001, pp. 1652-1657.

[2] A. Woyte, V.V. Thong, R. Belmans, and J. Nijs, "Voltage fluctuations on distribution level introduced by photovoltaic systems," IEEE Trans. Energy Convers., vol. 21, no. 1, pp. 202-209, March 2006.

[3] Y.T. Tan, D.S. Kirschen, and N. Jenkins, "A model of PV generation suitable for stability analysis," IEEE Trans. Energy Convers., vol. 19, no. 4, pp. 748-755, Dec 2004.

[4] T. Kinjo, T. Senjyu, N. Urasaki, and H. Fujita, "Output levelling of renewable energy by electric double layer capacitor applied for energy storage system," IEEE Trans. Energy Convers., vol. 21, no.1, pp. 221- 227, March 2006.

[5] Md. H. Rahman and S. Yamashiro, "Novel distributed power generating system of PV-ECaSS using solar energy estimation," IEEE Trans. Energy Convers., vol. 22, no.2, pp. 358-367, June 2007.

[6] J. P. Barton and D. G. Infield, "A probabilistic method for calculating the usefulness of a store with finite energy capacity for smoothing electricity generation from wind and solar power," Journal of Power Sources., vol. 162, pp. 943948, 2006.

[7] R. Wanger, "Large lead/acid batteries for frequency regulation, load levelling and solar power applications," Journal of Power Sources, vo. 67, pp. 163-172, 1997.

[8] H. Sugihara, S. Nishikawa, and Y. Kimura, "Observation of the hybrid system using photovoltaic and sodium-sulphur battery,"in Proc. JSES/JWEA Joint Conference, 2001, pp. 13-16.

[9] H. Miyauchi, K. Eguchi, and H. Hayashi, "SEMS to power quality improvement," in Proc. IEEJ Conference of Power and Energy Society, 2002, pp. 110-115.

[10] K. Kobayashi, I. Tanako, and Y. Sawada, "A study of a two stage maximum power point tracking control of a photovoltaic system under partially shaded insolation conditions," Solar Energy Materials \& Solar Cells, vol. 90, pp. 2975-2988, 2006.

[11] N. Femia, G. Petrone, G. Spagnuolo, and M. Vitelli, "Optimization of perturb and observe maximum power point tracking method," IEEE Trans. Power Electron., vol. 20, no. 4, pp. 963-973, July 2006.

[12] C. Hua, J. Lin, and C. Shen, "Implementation of a DSP controlled photovoltaic system with peak power tracking," IEEE Trans. Ind. Electron., vol. 45, no. 1, pp. 99-107, Feb. 1998.

[13] [Online]. Available: http://www.electricitystoarge.com

[14] T. Senjyu, T. Kaneko, A. Yona, N. Urasaki, T. Funabashi, F. Yamada, and S. Sugimoto, "Output power control for large wind power penetration in small power system," in Proc. IEEE PES General Meeting, sessionwindpower, CD-ROM, 2007.

[15] [Online]. Available: http://www.powerlight.com/ success/ pdf/ LVVWDRonzone Reservoir.pdf.

[16] [Online]. Available: http://www.xantrex.com/web/ id/ 214/ $\mathrm{p} / 1840 / \mathrm{pt} / 23 /$ product.asp. 